\title{
Distribution and transferability of plasmids encoding trimethoprim resistance in urinary pathogens from Greece
}

\author{
A. TSAKRIS, A. P. JOHNSON*t, R. C. GEORGEt, S. MEHTAR and A. C. VATOPOULOS
}

Department of Microbiology, North Middlesex Hospital, London N18 1QX, tDivision of Hospital Infection, Central Public Health Laboratory, Colindale Avenue, London NW9 5HT and $\ddagger$ Department of Microbiology, Hippocration General Hospital, Athens 11527, Greece

\begin{abstract}
Summary. Of 505 strains of Enterobacteriaceae responsible for significant bacteriuria and isolated from hospital patients in two Greek cities in 1989, 151 strains $(30 \%)$ were resistant to trimethoprim (MIC $\geq 4 \mathrm{mg} / \mathrm{L}$ ) and $220(44 \%)$ were resistant to sulphamethoxazole (MIC $\geq$ $64 \mathrm{mg} / \mathrm{L}) ; 127(84 \%)$ of the trimethoprim-resistant strains exhibited high-level resistance (MIC $>1024 \mathrm{mg} / \mathrm{L})$ and $121(80 \%)$ were additionally resistant to four or more other antibiotics. Plasmids were detected in $141(93 \%)$ of the trimethoprim-resistant strains. Trimethoprim resistance was encoded on self-transmissible plasmids in $79(52 \%)$ of the resistant strains, and in a further seven strains $(5 \%)$, plasmids coding for trimethoprim resistance could be mobilised by $\mathrm{X}^{+}$factor. Co-transfer of various other antimicrobial resistances with trimethoprim resistance was observed, tetracycline resistance being the most common. The low degree of linkage observed between trimethoprim resistance and resistance to streptomycin and spectinomycin suggests that $\mathrm{Tn} 7$ is relatively uncommon in Greece. Classification of trimethoprim-resistance plasmids on the basis of their antimicrobialresistance patterns and molecular mass revealed 39 different profiles. Overall, these findings differ from those from other European countries where the prevalence of transferable highlevel trimethoprim resistance is low and where chromosomal Tn7-encoded trimethoprim resistance is common.
\end{abstract}

\section{Introduction}

Trimethoprim exerts its antibacterial activity by inhibiting the bacterial enzyme dihydrofolate reductase (DHFR) which is involved in the synthesis of tetrahydrofolate, an essential precursor of several amino acids and nucleotides. ${ }^{1}$ Trimethoprim acts synergically with sulphonamides, which also inhibit tetrahydrofolate biosynthesis but at an earlier stage in the synthetic pathway. ${ }^{1}$ However, resistance to trimethoprim has been documented in various clinically important bacteria. High-level trimethoprim resistance (MIC > $1024 \mathrm{mg} / \mathrm{L}$ ), which may be encoded on plasmids, transposons or chromosomal DNA, usually results from the production of a modified form of DHFR which is unaffected by trimethoprim. ${ }^{2}$ Lowlevel resistance (MIC 4-1024 mg/L) also occurs and may similarly result from the production of modified DHFR or from other mechanisms such as reduced bacterial permeability to trimethoprim and other bacterial agents. $^{2,3}$

When trimethoprim was introduced into clinical use in 1968, it was available only in combination with sulphamethoxazole and this mixture was given the

Received 6 July 1990; accepted 8 Aug. 1990.

* Correspondence should be sent to Dr A. P. Johnson. generic name co-trimoxazole. In 1972, trimethoprim became available for use as a single agent in Finland and this occurred in other countries soon afterwards. In Greece, however, the combination of trimethoprim and sulphamethoxazole is still used in preference to trimethoprim alone, and, for this reason, antibiotic sensitivity testing in Greek hospitals is performed exclusively with disks containing a combination of these two antimicrobial agents. ${ }^{4}$ Therefore, it is impossible to assess from these data the incidence of resistance to trimethoprim alone. Because of this lack of information on the epidemiology of trimethoprim resistance in Greece, we have surveyed a collection of urinary tract pathogens isolated in two Greek cities during 1989 for resistance to this antibiotic. We report here the incidence of both high- and low-level resistance to trimethoprim, the frequency of plasmidmediated resistance and the basic characteristics of the R-plasmids involved.

\section{Materials and methods}

\section{Bacteria}

During the first 6 months of 1989, 505 strains of Enterobacteriaceae belonging to six different genera 
were obtained from separate patients with significant bacteriuria $\left(>10^{5} \mathrm{cfu} / \mathrm{ml}\right)$ in five Greek hospitals (three in Athens, two in Thessaloniki).

Escherichia coli strains 20R764 $\left(\right.$ lac $^{+}$rif $\left.^{\mathrm{R}}\right)$ and 26R793 $\left(\mathrm{lac}^{-}\right.$rif $^{\mathrm{R}}$ ) (kindly provided by Dr E. J. Threlfall, Division of Enteric Pathogens, Central Public Health Laboratory) were used as recipients in resistance-transfer experiments, and $E$. coli strain $18 \mathrm{R} 951$ containing the $\mathrm{X}^{+}$fertility factor ${ }^{5}$ was used in experiments to mobilise non-self-transferable plasmids encoding trimethoprim resistance. For the estimation of the size of plasmids, $E$. coli strains 39R861 and V517 which harbour plasmids of known molecular mass, were used as standards. ${ }^{6,7}$

\section{Determination of MIC}

MICs of trimethoprim and sulphamethoxazole were determined by an agar dilution method with IsoSensitest Agar (Oxoid) supplemented with lysed blood $5 \% \mathrm{v} / \mathrm{v}$. Serial doubling concentrations of each antimicrobial agent were incorporated into the agar, and plates were inoculated with a multipoint inoculator (Denley Instruments) with an inoculum of $10^{4} \mathrm{cfu} / \mathrm{spot}$. High-level resistance to trimethoprim was defined as MIC $>1024 \mathrm{mg} / \mathrm{L}$ and low-level resistance as MIC 4-1024 mg/L. ${ }^{8}$ Resistance to sulphamethoxazole was defined as MIC $\geqslant 64 \mathrm{mg} / \mathrm{L}$. The MICs of other antibiotics (ampicillin, cephalothin, chloramphenicol, tetracycline, amikacin, gentamicin, netilmicin, streptomycin, spectinomycin and tobramycin) were determined (as described above) for trimethoprim-resistant strains only. The levels of resistance were defined according to the recommendations of a Working Party of the British Society for Antimicrobial Chemotherapy. ${ }^{9}$

\section{Resistance-transfer experiments}

Bacterial strains resistant to trimethoprim were tested for their ability to transfer resistance to recipient strains. Overnight broth cultures of donor and recipient cultures were mixed in a ratio of $1: 10$ and about $300 \mu \mathrm{l}$ of each mixture was spread over the surface of each of two nutrient-agar plates which were incubated for $18 \mathrm{~h}$ at $37^{\circ} \mathrm{C}$ and $28^{\circ} \mathrm{C}$ respectively. The organisms were washed from the agar surface with phosphatebuffered saline, and transconjugants were selected by plating serial dilutions of the organism suspensions on nutrient-agar plates containing trimethoprim $2 \mathrm{mg} / \mathrm{L}$ and rifampicin $90 \mathrm{mg} / \mathrm{L}$.

\section{Mobilisation of plasmids}

Strains which failed to transfer trimethoprim resistance were investigated further for the presence of nonself-transferable plasmids, by mobilisation with the transfer factor $\mathrm{X}^{+}$employing the method described by Young et al. ${ }^{10}$

\section{Isolation of plasmid DNA}

Trimethoprim-resistant clinical isolates and transconjugants (one per donor strain) were analysed for plasmids by the method of Kado and Liu. ${ }^{11}$ Plasmids were separated by electrophoresis in agarose $0.8 \% \mathrm{w} / \mathrm{v}$ gels, at $100 \mathrm{~V}$ for $2.5 \mathrm{~h}$, stained with ethidium bromide and visualised by UV transillumination.

\section{Results}

\section{Incidence of trimethoprim and sulphamethoxazole resistance}

Of the 505 clinical isolates, $57 \%$ were $E$. coli, $16 \%$ Proteus spp., 12\% Klebsiella spp., 10\% Enterobacter spp., 4\% Serratia spp. and 0.6\% Citrobacter spp.; 151 isolates $(30 \%)$ were resistant to trimethoprim and 220 (44\%) were resistant to sulphamethoxazole; 132 strains $(26 \%)$ were resistant to both drugs (table I). Among the 151 trimethoprim-resistant strains, $127(84 \%)$ exhibited high-level resistance. When strains from Athens and Thessaloniki were compared, there was no appreciable difference either in the overall incidence of trimethoprim resistance $(29 \%$ in Athens versus $33 \%$ in Thessaloniki) or in the incidence of trimethoprim resistance in the various genera, with the exception of Enterobacter spp. (53\% in Athens versus $88 \%$ in Thessaloniki).

Table I. Proportion of strains resistant to trimethoprim, sulphamethoxazole or both antibiotics

\begin{tabular}{|c|c|c|c|c|c|}
\hline \multirow{2}{*}{ Species } & \multirow{2}{*}{$\begin{array}{l}\text { Number of } \\
\text { strains tested }\end{array}$} & \multicolumn{4}{|c|}{ Number $(\%)$ of strains resistant to } \\
\hline & & $\mathrm{Tp}(2 \mathrm{mg} / \mathrm{L})$ & $\mathrm{Tp}(1024 \mathrm{mg} / \mathrm{L})$ & $\mathrm{Su}(32 \mathrm{mg} / \mathrm{L})$ & $\begin{array}{c}\mathrm{Tp}(2 \mathrm{mg} / \mathrm{L}) \\
+\mathrm{Su}(32 \mathrm{mg} / \mathrm{L})\end{array}$ \\
\hline E. coli & 289 & $64(22)$ & $57(20)$ & $118(41)$ & $56(19)$ \\
\hline Proteus spp. & 81 & $21(26)$ & $15(19)$ & $25(31)$ & $16(20)$ \\
\hline Klebsiella spp. & 62 & $24(39)$ & $21(34)$ & $35(52)$ & $22(35)$ \\
\hline Enterobacter spp. & 50 & $32(64)$ & $27(54)$ & $34(68)$ & $29(58)$ \\
\hline Serratia spp. & 20 & $9(45)$ & $6(30)$ & $10(50)$ & $8(40)$ \\
\hline Citrobacter spp. & 3 & $1(33)$ & $1(33)$ & 1(33) & $1(33)$ \\
\hline Total & 505 & $151(30)$ & $127(25)$ & $220(44)$ & $132(26)$ \\
\hline
\end{tabular}

Tp, trimethoprim; Su, sulphamethoxazole. 


\section{Resistance to other antibiotics}

Of the trimethoprim-resistant strains (MIC $\geqslant 4 \mathrm{mg}$ / L), $80 \%$ were also resistant to four or more other antimicrobial agents. Resistance to sulphamethoxazole was the most common other resistance character $(87 \%)$ amongst the trimethoprim-resistant strains followed by ampicillin $(79 \%)$, tetracycline $(72 \%)$, cephalothin $(66 \%)$, chloramphenicol $(61 \%)$, streptomycin $(51 \%)$ and spectinomycin $(39 \%) ; 30 \%$ of the trimethoprim-resistant strains were resistant to both streptomycin and spectinomycin. More strains were resistant to tobramycin $(43 \%)$ and netilmicin $(40 \%)$ than to amikacin $(30 \%)$ and gentamicin $(24 \%)$.

\section{Transfer of trimethoprim resistance}

Transfer of trimethoprim resistance was observed in $86(57 \%)$ of the 151 resistant strains (table II) and the incidences of transferable resistance in Athens and Thessaloniki were virtually identical. However, six of these 86 strains (five strains of Enterobacter spp.

Table II. Transferability of trimethoprim-resistance in trimethoprim-resistant $\left(\mathrm{Tp}^{\mathrm{R}}\right)$ strains

\begin{tabular}{|c|c|c|c|c|}
\hline \multirow{3}{*}{ Species (n) } & \multicolumn{4}{|c|}{$\begin{array}{c}\text { Number of strains of donor resistance } \\
\text { phenoptype }\end{array}$} \\
\hline & \multicolumn{2}{|c|}{ High level $T p^{R}$} & \multicolumn{2}{|c|}{ Low level $T p^{R}$} \\
\hline & $\operatorname{tra}+$ & $\operatorname{tra}-$ & $\operatorname{tra}+$ & $\operatorname{tra}-$ \\
\hline E. coli $(64)$ & $40^{*}$ & 17 & 0 & 7 \\
\hline Proteus spp. (21) & 6 & 9 & 0 & 6 \\
\hline Klebsiella spp. (24) & 12 & 9 & 2 & 1 \\
\hline Enterobacter spp. (32) & 22 & 5 & 0 & 5 \\
\hline Serratia spp. (9) & 4 & 2 & 0 & 3 \\
\hline Citrobacter spp. (1) & 0 & 1 & 0 & 0 \\
\hline Total & 84 & 43 & 2 & 22 \\
\hline
\end{tabular}

tra + , Transferable; tra -, non-transferable.

* Seven $E$. coli strains required $\mathrm{X}^{+}$factor for transfer. and one $E$. coli strain) transferred resistance only at $28^{\circ} \mathrm{C}$. Seven strains of $E$. coli contained non-selftransferable plasmids and required the $\mathrm{X}^{+}$factor for their mobilisation. Transfer of trimethoprim resistance was higher among $E$. coli and Enterobacter spp. than in the other species examined (table II).

Of the 24 strains with low-level trimethoprim resistance, only two (both Klebsiella spp.) had transferable resistance (table II). The MIC of trimethoprim for both of these strains was $256 \mathrm{mg} / \mathrm{L}$. Among the 127 strains with high-level resistance to trimethoprim, $84(66 \%)$ exhibited transferable resistance (table II). Overall, the frequency of transfer of trimethoprim resistance varied from $1.6 \times 10^{-2}$ to $2.9 \times 10^{-8}$ transconjugants per donor, with the majority of strains exhibiting a transfer frequency of $10^{-3}-10^{-4}$.

\section{Linkage of trimethoprim resistance with resistance to other antimicrobials}

Resistance profiles were determined for 70 transconjugants obtained from different donors that carried single plasmids identical in size to plasmids present in their respective donors. Only $31(44 \%)$ were resistant to sulphamethoxazole despite the fact that $90 \%$ of the donor strains exhibited resistance to this drug. Less than half of the transconjugants showed linkage of trimethoprim resistance with resistance to ampicillin $(47 \%)$ or chloramphenicol $(39 \%)$. Linkage was highest with tetracycline resistance $(57 \%)$ (table III). Cotransfer of trimethoprim and streptomycin resistance determinants was demonstrated in $23 \%$ of the transconjugants and with spectinomycin resistance in $20 \%$. However, co-transfer of trimethoprim resistance with resistance to both streptomycin and spectinomycin was found in only $11 \%$ of the transconjugants. Resistance to tobramycin was present in $46 \%$ of the transconjugants, $39 \%$ were resistant to netilmicin, $31 \%$ to amikacin, but only $20 \%$ exhibited resistance to gentamicin (table III).

Table III. Co-transfer of trimethoprim resistance with resistance to other antimicrobial agents in transconjugants that gained only a single plasmid*

\begin{tabular}{|c|c|c|c|c|c|c|}
\hline \multirow{2}{*}{$\begin{array}{l}\text { Resistance } \\
\text { character }\end{array}$} & \multicolumn{6}{|c|}{ Number of strains of each species from which indicated antimicrobial resistance was co-transferred } \\
\hline & E. $\operatorname{coli}(\mathrm{n}=28)$ & $\begin{array}{l}\text { Proteus spp. } \\
\quad(n=6)\end{array}$ & $\begin{array}{l}\text { Klebsiella spp. } \\
\quad(\mathrm{n}=14)\end{array}$ & $\begin{array}{c}\text { Enterobacter spp. } \\
\quad(n=18)\end{array}$ & $\begin{array}{l}\text { Serratia spp. } \\
\quad(n=4)\end{array}$ & $\begin{array}{c}\text { Total }(\%) \\
(n=70)\end{array}$ \\
\hline Sulphamethoxazole & 11 & 4 & 3 & 11 & 2 & 31(44) \\
\hline Ampicillin & 12 & 3 & 6 & 10 & 2 & 33(47) \\
\hline Cephalothin & 0 & 0 & 6 & 2 & 0 & $8(11)$ \\
\hline Chloramphenicol & 11 & 2 & 2 & 11 & 1 & $27(39)$ \\
\hline Tetracycline & 20 & 0 & 13 & 5 & 2 & $40(57)$ \\
\hline Streptomycin & 11 & 0 & 0 & 5 & 0 & $16(23)$ \\
\hline Spectinomycin & 3 & 1 & 0 & 10 & 0 & $14(20)$ \\
\hline Gentamicin & 2 & 0 & 2 & 9 & 1 & $14(20)$ \\
\hline Tobramycin & 2 & 0 & 12 & 17 & 1 & $32(46)$ \\
\hline Netilmicin & 2 & 0 & 12 & 12 & 1 & $27(39)$ \\
\hline Amikacin & $\overline{1}$ & 0 & 12 & 8 & 1 & $22(31)$ \\
\hline
\end{tabular}

* Transconjugants in which plasmid differed in size from plasmids present in donor strain were not included. 


\section{Characterisation of $R$-plasmids}

Plasmids were detected in 141 (93\%) trimethoprimresistant strains. Although all strains with transferable resistance carried one or more plasmids, $85 \%$ of strains with non-transferable resistance also contained plasmids. At least one plasmid was visualised in each of 86 transconjugants tested; 75 of the transconjugants contained a single plasmid which, in all but three, were in the size range $60-130 \mathrm{Mda}$ - the remaining three plasmids were c. $30 \mathrm{Mda}$ in size. Seven transconjugants obtained by mobilisation of the donor plasmid with the $\mathrm{X}^{+}$factor were classified as containing a single transferred plasmid, even though the $\mathrm{X}^{+}$factor was also present. In transconjugants that exhibited resistance to six or fewer antimicrobials, the plasmids frequently were in the size range 60-100 Mda, whereas in those that exhibited resistance to more than six antimicrobials, the plasmid was $\geqslant 100 \mathrm{Mda}$ in size. In five transconjugants, the plasmid differed in size from those identified in their donors, and in a further 11 transconjugants, two or more plasmids were cotransferred. These two groups of transconjugants were not included in subsequent analyses.

Analysis of the antimicrobial resistance patterns and molecular sizes of plasmids in trimethoprimresistant transconjugants revealed 39 different profiles. The most commonly observed plasmid profiles are shown in table IV. Interestingly, plasmids with the same profile were sometimes seen in transconjugants derived from donor strains belonging to different genera. Furthermore, trimethoprim-resistance plasmids with the same profile occurred in donor strains obtained from both Athens and Thessaloniki (table IV).

\section{Discussion}

Trimethoprim, in combination with a sulphonamide, has been used extensively in Greece during the last 20 years, mainly for the treatment of urinary tract infections. The results of our study show that, currently, $30 \%$ of Enterobacteriaceae isolates from urinary tract infections in Greece are resistant to trimethoprim, similar rates of resistance being seen in two cities, namely Athens and Thessaloniki. This high incidence of resistance is comparable to that seen in France $^{12}$ and Finland ${ }^{13}$ but appears lower than that seen in developing countries, such as India, ${ }^{10}$ Nigeria $^{14}$ or South Africa, ${ }^{15}$ where more than half of the isolates are resistant. The association of resistance to trimethoprim and multi-resistance, which has been reported previously, ${ }^{16}$ was confirmed in the present study, in that $80 \%$ of the trimethoprim-resistant strains were also resistant to four or more other antibiotics.

A further point of interest is that, among trimethoprim-resistant strains from Greece, a high proportion (84\%) exhibited high-level resistance. Similar proportions of strains with high-level resistance have been reported from India ${ }^{10}$ and Chile, ${ }^{17}$ although lower proportions have been observed in other surveys. ${ }^{15,18,19}$ Several European studies ${ }^{19-22}$ have shown that only a small proportion of strains with high-level trimethoprim resistance exhibit transferable resistance, possibly due to the location of the resistance gene on the chromosome. ${ }^{23}$ In contrast, in the present survey, $66 \%$ of the strains with high-level trimethoprim resistance showed transferable resistance. The observation that two strains with low-level resistance (MIC $256 \mathrm{mg} / \mathrm{L}$ ) to trimethoprim could also transfer their resistance, confirms that this form of resistance can be plasmid-mediated. ${ }^{24,25}$

Analysis of transconjugants revealed that other antimicrobial resistances were co-transferred with resistance to trimethoprim. Tetracycline resistance showed the highest linkage, possibly reflecting the high consumption of tetracycline in Greece for a large number of common infections. In contrast, linkage of trimethoprim resistance and sulphamethoxazole resistance was surprisingly low, despite the fact that almost all the trimethoprim-resistant clinical isolates were resistant to the latter drug. This suggests that, despite the exclusive use of co-trimoxazole in Greece, resistance to trimethoprim and to sulphamethoxazole have evolved separately.

The low level of co-transfer of trimethoprim resistance with resistance to both streptomycin and

Table IV. Characterisation of plasmids* most commonly found in trimethoprim-resistant transconjugants

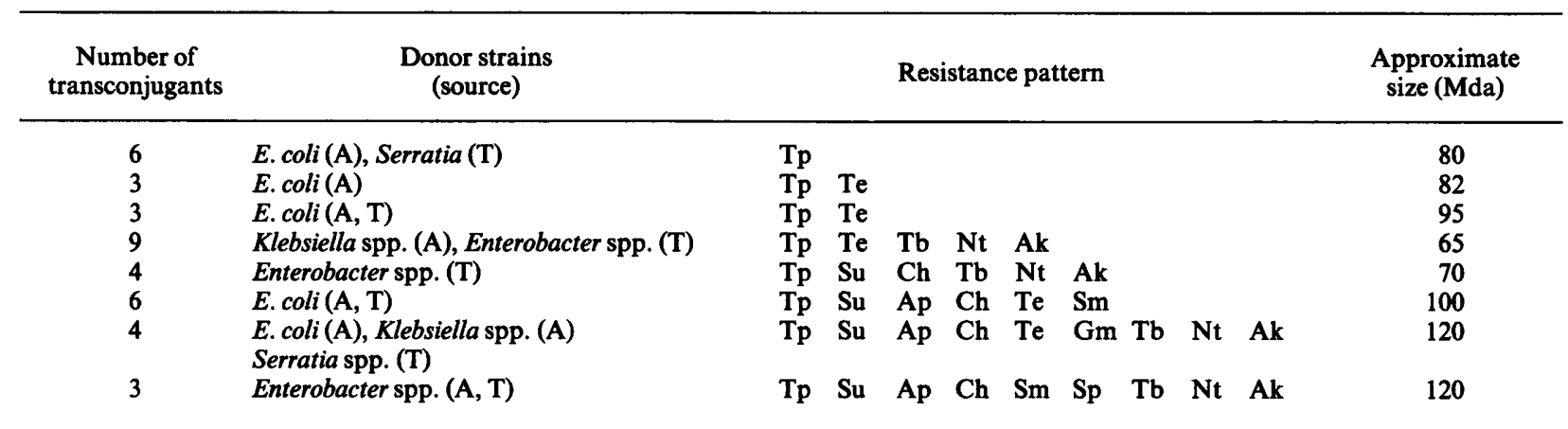

\footnotetext{
* Plasmids observed in transconjugants derived from three or more donor strains.
}

A, Athens; T, Thessaloniki. Ak, Amikacin; Ap, ampicillin; Ch, chloramphenicol; Gm, gentamicin; Nt, netilmicin; Sp, spectinomycin; Sm, streptomycin; Su, sulphamethoxazole; Te, tetracycline; Tb, tobramycin; Tp, trimethoprim. 
spectinomycin suggests that the transposon $\operatorname{Tn} 7$ is not a major determinant of trimethoprim resistance in Greece. DNA hybridisation experiments, with a $\operatorname{Tn} 7$ probe, confirm this suggestion (unpublished observations). Resistance to tobramycin, netilmicin and amikacin was co-transferred with trimethoprim resistance more frequently than was gentamicin resistance. This may, at least in part, reflect the relatively low usage of gentamicin compared to other aminoglycosides in Greece. In addition, the most common aminoglycoside-modifying enzyme found in a recent survey of Greek isolates of Enterobacter cloacae was AAC (6 $\left.6^{\prime}\right)$ I (unpublished observations) which is active against tobramycin, netilmicin and amikacin. ${ }^{26}$ Therefore, it is possible that the current findings reflect, in some instances, linkage of trimethoprim resistance with resistance to aminoglycosides mediated by production of AAC $\left(6^{\prime}\right) \mathrm{I}$.

In Greece, plasmid-mediated resistance seems to be the prevalent cause of resistance to trimethoprim

\section{References}

1. Smith JT, Amyes SGB. Bacterial resistance to antifolate chemotherapeutic agents mediated by plasmids. $\mathrm{Br} \mathrm{Med}$ Bull 1984; 40: 42-46.

2. Amyes SGB. The success of plasmid-encoded resistance genes in clinical bacteria. $J$ Med Microbiol 1989; $28: 73-83$.

3. Gutmann L, Williamson R, Moreau N et al. Cross-resistance to nalidixic acid, trimethoprim, and chloramphenicol associated with alterations in outer membrane proteins of Klebsiella, Enterobacter, and Serratia. J Infect Dis 1985; 151 : 501-507.

4. Greek Society for Microbiology. Antibiotic resistance among gram-negative bacilli in 19 Greek hospitals. J Hosp Infect 1989; 14: 177-181.

5. Anderson ES, Threlfall EJ. The characterization of plasmids in the enterobacteria. $J$ Hyg 1974; 72: 471-487.

6. Threlfall EJ, Rowe B, Ferguson JL, Ward LR. Characterization of plasmids conferring resistance to gentamicin and apramycin in strains of Salmonella typhimurium phage type 204c isolated in Britain. J Hyg 1986; 97: 419-426.

7. Macrina FL, Kopecko DL, Jones KR, Ayers DJ, McCowen SM. A multiple plasmid-containing Escherichia coli strain: convenient source of size reference plasmid molecules. Plasmid 1978; 1 : 417-420.

8. Acar JF, Goldstein FW. Genetic aspects and epidemiologic implications of resistance to trimethoprim. Rev Infect Dis $1982 ; 4: 270-275$.

9. Working Party of the British Society for Antimicrobial Chemotherapy. Breakpoints in in-vitro antibiotic sensitivity testing. $J$ Antimicrob Chemother $1988 ; 21: 701-710$.

10. Young H-K, Jesudason MV, Koshi G, Amyes SGB. Trimethoprim resistance amongst urinary pathogens in South India. $J$ Antimicrob Chemother 1986; 17:615-621.

11. Kado CI, Liu S-T. Rapid procedure for detection and isolation of large and small plasmids. J Bacteriol 1981; 145: 13651373.

12. Goldstein FW, Papadopoulou B, Acar JF. The changing pattern of trimethoprim resistance in Paris, with a review of worldwide experience. Rev Infect Dis 1986; 8: 725-737.

13. Huovinen P, Pulkkinen L, Helin H-L, Mäkilä M, Toivanen P. Emergence of trimethoprim resistance in relation to drug consumption in a Finnish hospital from 1971 through 1984. Antimicrob Agents Chemother 1986; 29 : 73-76. among urinary tract pathogens. Analysis of trimethoprim-resistant transconjugants revealed a variety of plasmids, which differed on the basis of their molecular size and antimicrobial-resistance patterns. Plasmids with identical antimicrobial-resistance patterns and molecular sizes were observed both in transconjugants derived from donors belonging to different genera of bacteria, and in transconjugants derived from donors isolated from the two different cities included in the study, indicating that such plasmids are possibly widespread. However, it remains to be confirmed that plasmids with the same resistance profile and molecular size are, in fact, identical. Clearly, further molecular and genetic studies will be required to determine the relationship, if any, between these plasmids. It is hoped that such studies will result in an increased understanding of the epidemiology of resistance to trimethoprim.

We thank Drs B. Cookson, T. L. Pitt and N. Woodford for helpful discussion.

14. Lamikrana A, Ndep RB. Trimethoprim resistance in urinary tract pathogens in two Nigerian hospitals. $J$ Antimicrob Chemother 1989; 23: 151-154.

15. Wylie BA, Koornhof HJ. Trimethoprim resistance in Gramnegative bacteria isolated in South Africa. $J$ Antimicrob Chemother $1989 ; 24$ : 973-982.

16. Datta N, Dacey S, Hughes V et al. Distribution of genes for trimethoprim and gentamicin resistance in bacteria and their plasmids in a general hospital. J Gen Microbiol 1980; 118: 495-508.

17. Urbina R, Prado V, Canelo E. Trimethoprim resistance in enterobacteria isolated in Chile. $J$ Antimicrob Chemother 1989 ; 23 : 143-149.

18. Amyes SGB. The detection and incidence of transferable trimethoprim resistance. Health Bull (Edinb) 1983; 41 : 100-107.

19. Huovinen P, Pulkkinen L, Toivanen $P$. Transferable trimethoprim resistance in three Finnish hospitals. $J$ Antimicrob Chemother 1983; 12 : 249-256.

20. Amyes SGB, Doherty CJ, Young HK. High-level trimethoprim resistance in urinary bacteria. Eur J Clin Microbiol 1986; 5: 287-291.

21. Papadopoulou B, Gerbaud G, Courvalin P, Acar JF, Goldstein FW. Molecular epidemiology of resistance to trimethoprim in enterobacteria isolated in a Parisian hospital. Annals de l'Inst Pasteur Microbiol 1986; 137A : 239-251.

22. Chirnside ED, Emmerson AM, Smith JT. A follow-up survey of transferable, plasmid-encoded trimethoprim resistance in a general hospital (1975-1983). J Antimicrob Chemother $1985 ; 16: 419-434$.

23. Steen R, Skold O. Plasmid-borne or chromosomally-mediated resistance by $\operatorname{Tn} 7$ is the most common response to ubiquitous use of trimethoprim. Antimicrob Agents Chemother $1985 ; 27$ : 933-937.

24. Towner KJ, Pinn PA. A transferable plasmid conferring only a moderate level of resistance to trimethoprim. FEMS Microbial Lett 1981; 10: 271-272.

25. Young H-K, Jesudason MV, Koshi G, Amyes SGB. Unusual expression of new low-level-trimethoprim resistance plasmids. J Clin Microbiol 1986; 24 : 61-64.

26. Phillips I, Shannon K. Aminoglycoside resistance. Br Med Bull $1984 ; 40: 28-35$ 
